\title{
Racial and Ethnic Disparities in Incidence of SARS-CoV-2 Infection, 22 US States and DC, January 1-October 1, 2020
}

\author{
NaTasha D. Hollis, ${ }^{1}$ Wen Li, ${ }^{1}$ Miriam E. Van Dyke, Gibril J. Njie, \\ Heather M. Scobie, Erin M. Parker, Ana Penman-Aguilar, ${ }^{2}$ Kristie E.N. Clarke ${ }^{2}$
}

We examined disparities in cumulative incidence of severe acute respiratory syndrome coronavirus 2 by race/ethnicity, age, and sex in the United States during January 1-October 1, 2020. Hispanic/Latino and nonHispanic Black, American Indian/Alaskan Native, and Native Hawaiian/other Pacific Islander persons had a substantially higher incidence of infection than nonHispanic White persons.

$\mathrm{H}$ ealth disparities among racial/ethnic minority groups in the United States are closely related to structural inequities in social determinants of health. Some racial/ethnic minority groups have disproportionate rates of underlying conditions that increase the risk for severe illness from coronavirus disease (COVID-19) (1,2). Certain groups are overrepresented in occupations that require public contact, have crowded conditions, or are unamenable to telework, increasing the risk for exposure to severe acute respiratory infection coronavirus 2 (SARS-CoV-2), the virus that causes COVID-19 $(3,4)$. Structural inequities in housing, education, wealth, and healthcare access also increase disparities in infection and COVID-related illness and death (5-8).

We conducted an intersectional analysis by race/ ethnicity, age, and sex to identify disparities in SARSCoV-2 incidence using data from multiple US jurisdictions. Monitoring these disparities is critical for guiding action to reduce health inequities.

Author affiliations: Centers for Disease Control and Prevention, Atlanta, Georgia, USA (N.D. Hollis, W. Li, M.E. Van Dyke,

G.J. Njie, H.M. Scobie, E.M. Parker, A. Penman-Aguilar,

K.E.N. Clarke); Commissioned Corps of the US Public Health

Service, Atlanta (N.D. Hollis, H.M. Scobie, E. Parker, K.E.N. Clarke)

DOI: https://doi.org/10.3201/eid2705.204523

\section{The Study}

We analyzed SARS-CoV-2 infections reported to the Centers for Disease Control and Prevention (https:/ / data.cdc.gov/browse?tags=covid-19) by jurisdictional health departments. To minimize information bias, we included only jurisdictions reporting $\geq 30 \%$ of cases (https:// protect-public.hhs.gov) and $\geq 70 \%$ completeness of race/ethnicity data of cases during January 1-October 1, 2020. We analyzed data on race/ethnicity, age, and sex in 1,751,627 cases from 22 US states and the District of Columbia (Table).

We determined cumulative incidence of infection per 100,000 population and cumulative incidence ratios (CIRs) with 95\% CIs by race/ethnicity, age, and sex. Patients were grouped as Hispanic or Latino (Hispanic), non-Hispanic American Indian or Alaska Native (AIAN), non-Hispanic Black or African American (Black), non-Hispanic Asian (Asian), non-Hispanic Native Hawaiian or other Pacific Islander (NHOPI), non-Hispanic White (White), or non-Hispanic of multiple races (multiple race). Of Hispanic persons in this sample, $53.8 \%$ identified as White, $33.2 \%$ as persons of multiple or other races, $1.7 \%$ as Black, $0.2 \%$ as Asian, and $0.2 \%$ as NHOPI; $10.5 \%$ of Hispanic persons were of unknown race. We used population denominators from the 2019 US Census (Annual County Resident Population Estimates by Age, Sex, Race, and Hispanic Origin, https://www.census.gov/programs-surveys/popest/technical-documentation/file-layouts. html). We considered CIR 95\% CIs excluding 1.0 to be significant. We assessed differences in rates by sex after adjusting for race/ethnicity and age using Analysis of Variance. We conducted statistical analyses using R version 4.0.0 (9). This study was conducted in

\footnotetext{
${ }^{1}$ These first authors contributed equally to this article.

${ }^{2}$ These senior authors contributed equally to this article..
} 
Table. Incidence of severe acute respiratory syndrome coronavirus 2 infections by sex, race/ethnicity, and age group, 22 US states and District of Columbia, January 1-October 1, 2020*

\begin{tabular}{|c|c|c|c|}
\hline Characteristic & $\begin{array}{c}\text { No. }(\%), n= \\
1,751,627 \dagger\end{array}$ & $\begin{array}{c}\text { Cumulative incidence } \\
(95 \% \mathrm{Cl}) \pm \S\end{array}$ & $\begin{array}{c}\text { Cumulative incidence } \\
\text { ratio }(95 \% \mathrm{Cl}) \S\end{array}$ \\
\hline \multicolumn{4}{|l|}{ Sex } \\
\hline $\mathrm{F}$ & $898,970(51.7)$ & $1,734(1,730-1,737)$ & Referent \\
\hline M & 841,487 (48.3) & $1,672(1,668-1,675)$ & $0.96(0.96-0.97)$ \\
\hline \multicolumn{4}{|l|}{ Race and ethnicity $\mathbb{T}$} \\
\hline Non-Hispanic White & 657,437 (47.7) & 935 (933-938) & Referent \\
\hline Non-Hispanic Black & $225,477(16.4)$ & $1,974(1,965-1,982)$ & $2.11(2.10-2.12)$ \\
\hline Non-Hispanic Asian & $33,703(2.4)$ & $874(865-884)$ & $0.93(0.92-0.95)$ \\
\hline Non-Hispanic multiple races & $22,650(1.6)$ & 957 (944-969) & $1.02(1.01-1.04)$ \\
\hline Non-Hispanic American Indian or Alaska Native & $19,259(1.4)$ & $2,274(2,242-2,306)$ & $2.43(2.40-2.47)$ \\
\hline Non-Hispanic Native Hawaiian or other Pacific Islander & $7,226(0.5)$ & $2,693(2,631-2,755)$ & $2.88(2.81-2.95)$ \\
\hline Hispanic or Latino & $375,418(27.3)$ & $2,860(2,850-2,869)$ & $3.06(3.05-3.07)$ \\
\hline Non-Hispanic other & $36,104(2.6)$ & NA & NA \\
\hline \multicolumn{4}{|l|}{ Age group, y } \\
\hline$<19$ & 191,303 (11.5) & $774(770-777)$ & $0.33(0.33-0.34)$ \\
\hline $20-34$ & 473,627 (28.4) & $2,316(2,310-2,323)$ & Referent \\
\hline $35-44$ & $270,405(16.2)$ & $2,146(2,138-2,154)$ & $0.93(0.92-0.93)$ \\
\hline $45-54$ & $258,400(15.5)$ & $2,060(2,052-2,068)$ & $0.89(0.89-0.89)$ \\
\hline $55-64$ & $216,848(13.0)$ & $1,591(1,584-1,597)$ & $0.69(0.68-0.69)$ \\
\hline $65-74$ & $128,348(7.7)$ & $1,220(1,213-1,226)$ & $0.53(0.52-0.53)$ \\
\hline $75-84$ & $74,539(4.5)$ & $1,366(1,356-1,376)$ & $0.59(0.59-0.59)$ \\
\hline$\geq 85$ & $51,472(3.1)$ & $2,283(2,263-2,303)$ & $0.99(0.98-0.99)$ \\
\hline \multicolumn{4}{|c|}{$\begin{array}{l}\text { *Data from District of Columbia and } 22 \text { US states: Alaska, Arkansas, Florida, Hawaii, lowa, Kansas, Massachusetts, Maine, Michigan, Minnesota, } \\
\text { Mississippi, Montana, Nebraska, New Hampshire, New Mexico, Nevada, Ohio, Oregon, Tennessee, Utah, Vermont, and Wisconsin. Data from Data } \\
\text { Collation and Integration for Public Health Event Responses platform (https://data.cdc.gov/browse?tags=covid-19). NA, not available. } \\
\text { †Missing sex data for } 11,170 \text { persons; race/ethnicity data for } 374,353 \text { persons; and age data for } 86,685 \text { persons (not included in percentage calculations) } \\
\text { †Cases per } 100,000 \text { persons. Population denominators from } 2019 \text { US Census (Annual County Resident Population Estimates by Age, Sex, Race, and } \\
\text { Hispanic Origin, https://www. census.gov/programs-surveys/popest/technical-documentation/file-layouts.html). } \\
\text { §Calculated using a normal approximation (Xu J, Kockanek KD, Murphy SL, Tejada-Vera B. Deaths: final data for 2007. National Center for Health } \\
\text { Statistics. } 2010 \text { [cited } 2020 \text { Oct } 16] \text {. https://www.cdc.gov/nchs/data/nvsr/nvsr58/nvsr58_19.pdf). } \\
\text { TNo measures were calculated for } 36,104 \text { Non-Hispanic persons of other races because of lack of population denominator information from US Census } \\
\text { Bureau. }\end{array}$} \\
\hline
\end{tabular}

accordance with applicable federal law and Centers for Disease Control and Prevention policy [45 Code of Federal Regulations part 46.102(1)(2)].

We found that most racial/ethnic minority groups had significantly higher cumulative incidence of SARSCoV-2 than did White persons (Table). Cumulative incidence ranged from 874 (95\% CI 865-884)/100,000 population in Asian persons to 2,860 (95\% CI 2,850$2,869) / 100,000$ population in Hispanic persons. CIRs were significantly higher among Black (2.11), AIAN (2.43), NHOPI (2.88), and Hispanic persons (3.06) compared with White persons; the CIR was nominally but significantly different for multiple race (1.02) and Asian persons (0.93). Cumulative incidence for men compared with women, when adjusted for both race/ethnicity and age, was similar ( $p=0.982$; data not shown).

Cumulative incidence of SARS-CoV-2 was significantly higher among most racial/ethnic minority groups than among White persons of the same age group (Figure 1; Appendix Table 1, https://wwwnc. cdc.gov/EID/article/27/5/20-4523-App1.pdf). Among Asian persons $<45$ or $\geq 75$ years of age, CIRs were lower (0.53-0.95) than among White persons. Among multiple race persons, results varied by age: CIRs were significantly lower among those $<19$ years of age (CIR 0.54,
95\% CI 0.52-0.56) and 20-34 years of age (CIR 0.88, 95\% CI $0.86-0.90$ ) but $» 4-6$ times higher among those $\geq 75$ years of age. Black, AIAN, NHOPI (except for persons aged $\geq 85$ ), and Hispanic persons had CIRs of 1.45-3.83 by age group.

We found differences in infection rates by sex within various racial/ethnic and age groups (CIRs 0.64-1.30) (Figure 2; Appendix Table 2). Overall, cumulative incidence among men in all racial/ethnic groups was significantly lower than among women (CIRs 0.85-0.97), with an exception among Asian men (CIR 1.05). Men who were Black and $\geq 65$ years of age, multiple race and 65-74 years of age, and Hispanic or White and 55-84 years of age had a higher cumulative incidence than women. Among NHOPI and AIAN persons, cumulative incidence was significantly lower than for White persons only for men 20-44 years of age.

\section{Conclusions}

Among $>1.75$ million persons with SARS-CoV-2 in 23 US jurisdictions during January 1-October 1, 2020, persons from most racial/ethnic minority groups had higher cumulative incidence than White persons. Hispanic persons had a 3.1-fold higher incidence and Black, AIAN, and NHOPI persons a $>2$-fold higher 


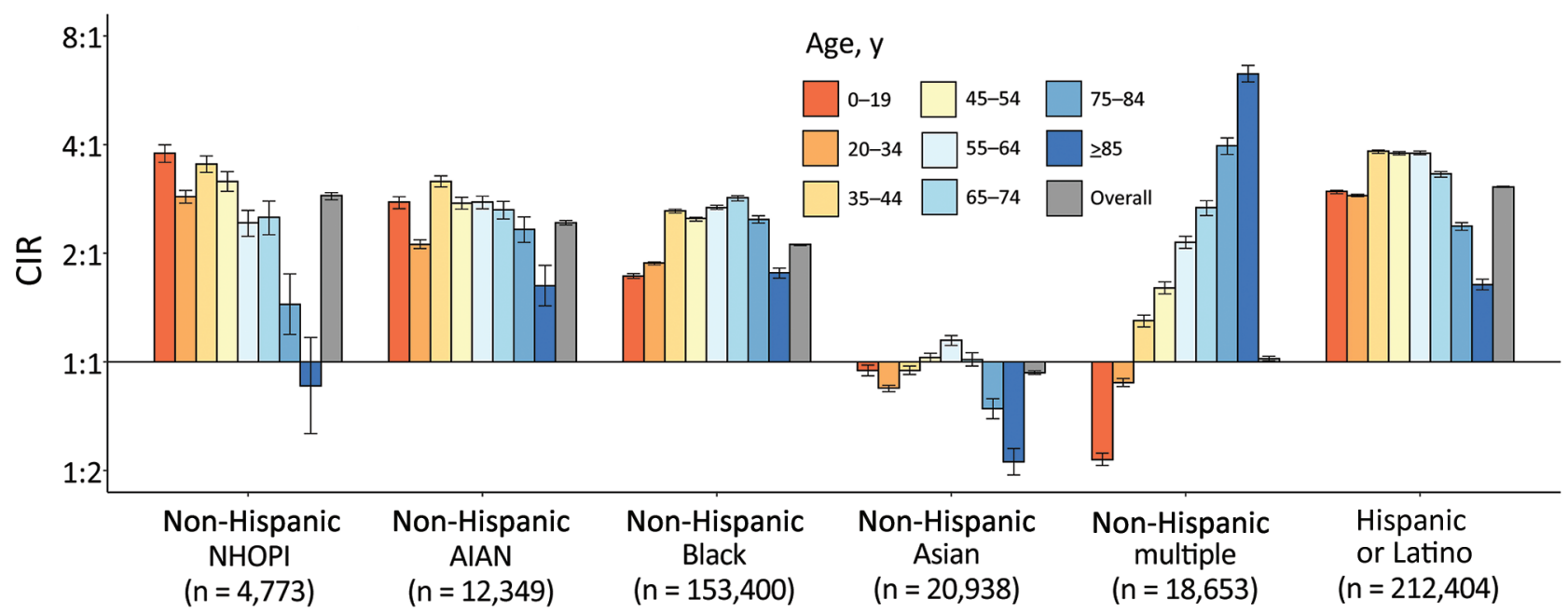

Figure 1. CIRs of severe acute respiratory syndrome coronavirus 2 among persons of different racial/ethnic groups compared with nonHispanic White persons, 22 US states and the District of Columbia, January 1-October 1, 2020. Ratios are displayed on binary logarithmic scale; error bars indicate 95\% Cls (Appendix Table 1, https://wwwnc.cdc.gov/EID/article/27/5/20-4523-App1.pdf). CIRs are displayed on binary logarithmic scale; error bars indicate $95 \% \mathrm{Cls}$. CIRs with error bars not crossing the origin $(1: 1)$ are significant $(p<0.05)$. AIAN, American Indian or Alaska Native; CIR, cumulative incidence ratio; NHOPI, Native Hawaiian or other Pacific Islander.

incidence of SARS-CoV-2 than did White persons. Racial/ethnic disparities varied by age group. Sex differences in cumulative incidence within racial/ ethnic groups were less pronounced than disparities between racial/ethnic groups.

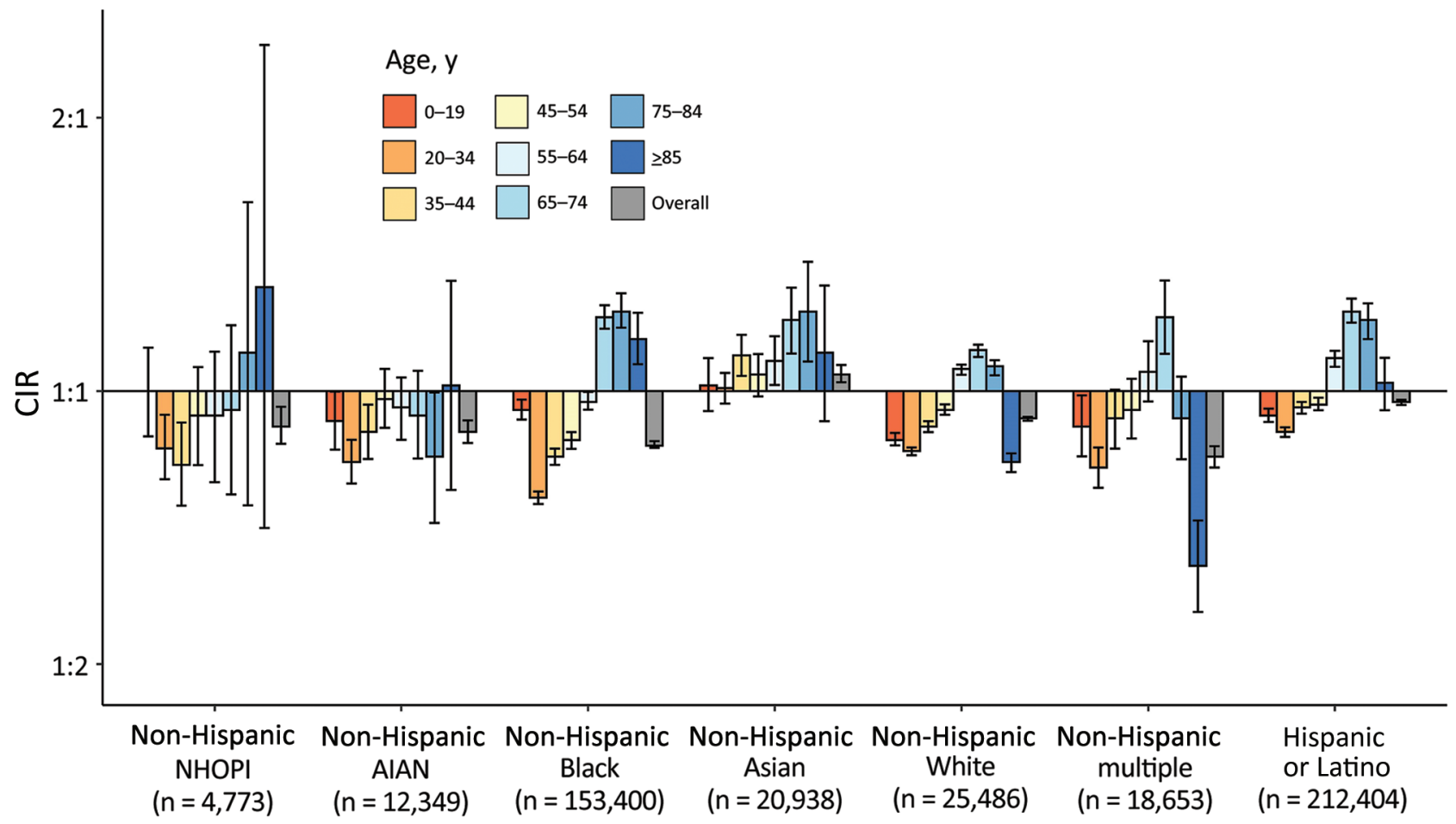

We found the highest incidence of infection among Hispanic persons, similar to findings of studies examining SARS-CoV-2 positivity rates in more limited US geographic areas (6,10-12). We also found high incidence among NHOPI persons. Previous analyses

Figure 2. CIRs of severe acute respiratory syndrome coronavirus 2 for male sex, compared with female sex, 22 US states and District of Columbia, January 1-October 1, 2020. Ratios are displayed on binary logarithmic scale; error bars indicate 95\% Cls (Appendix Table 2, https://wwwnc.cdc.gov/EID/article/27/5/20-4523-App1.pdf). CIRs are displayed on binary logarithmic scale; error bars indicate 95\% Cls. CIRs with error bars not crossing the origin $(1: 1)$ are significant $(p<0.05)$. AIAN, American Indian or Alaska Native; CIR, cumulative incidence ratio; NHOPI, Native Hawaiian or other Pacific Islander. 
have rarely disaggregated NHOPI persons, preventing detection of disparities. Although previous studies have shown higher rates of severe COVID-19 illness among men, we observed lower infection rates among men overall $(1,13)$.

Social determinants of health drive racial/ethnic disparities in disease incidence (3-8). For example, members of some racial/ethnic groups are overrepresented in the essential workforce and more likely to live in multigenerational or high-density housing, increasing the risk for SARS-CoV-2 exposure (https:/ / www.cdc.gov/coronavirus/2019-ncov/community/ health-equity/racial-ethnic-disparities/index.html). Outbreaks in some occupational settings have had racial/ethnic disparities in infection $(3,8)$. Employers, community organizations, healthcare systems, public health agencies, and governments can act to reduce racial/ethnic disparities in COVID-19 incidence by implementing flexible, nonpunitive leave policies (e.g., paid sick leave); equitable access to testing and screening programs, personal protective equipment, and vaccines; and policies that encourage physical distancing (14). In addition, public health officials can tailor COVID-19 prevention messaging to the languages and cultures of various racial/ethnic groups. Multisectoral partnerships could support COVID-19 mitigation strategies through initiatives that provide spaces for isolation or self-quarantine, safe transportation, free or reduced-cost broadband internet, and housing resources (14).

One limitation of this study is that underreporting to the Centers for Disease Control and Prevention database, which documented $78 \%$ of cases in selected jurisdictions, probably caused underestimates in calculated incidence. Second, selected jurisdictions comprise $31 \%$ of the US population; in these jurisdictions, NHOPI, White, AIAN, and multiple race persons are overrepresented and Asian, Hispanic, and Black persons underrepresented (Appendix Table 3). As a result, our findings are not nationally representative or generalizable. Third, we excluded persons of unknown race/ethnicity (24\%) from incidence calculations. Among persons of unknown race/ethnicity, 33\% specified race but not ethnicity; minority racial groups were overrepresented (Appendix Table 4). Fourth, cases among racial/ethnic minority groups might be underreported because of disparities in testing access (15). The third and fourth issues probably resulted in underestimation of racial/ethnic disparities. Finally, aggregation of NHOPI and Asian persons in $\geq 2$ jurisdictions probably resulted in underestimating incidence among NHOPI persons and overestimating among Asian persons.
In summary, documenting population-based racial/ethnic disparities in SARS-CoV-2 infection rates and how disparities vary by age and sex informs the development and implementation of equitable policies and intervention strategies. Strategies should prioritize collection and analysis of data relating to health equity and focus on mitigating disproportionate risks of exposure related to social determinants of health.

\section{Acknowledgments}

We thank Jayme Coyle for providing technical assistance and data visualization support. We also thank all COVID-19 response personnel at the Centers for Disease Control and Prevention for data collection, reporting, and guidance during the COVID-19 pandemic.

\section{About the Author}

Dr. Hollis is an epidemiologist in the National Center on Birth Defects and Developmental Disabilities, Centers for Disease Control and Prevention in Atlanta, Georgia, USA. Her research interests include improving health and well-being and decreasing disparities among vulnerable populations.

\section{References}

1. Garg S, Kim L, Whitaker M, O'Halloran A, Cummings C, Holstein R, et al. Hospitalization rates and characteristics of patients hospitalized with laboratory-confirmed coronavirus disease 2019-COVID-NET, 14 states, March 1-30, 2020. MMWR Morb Mortal Wkly Rep. 2020;69:458-64. https:/ / doi.org/10.15585/mmwr.mm6915e3

2. Raifman MA, Raifman JR. Disparities in the population at risk of severe illness from COVID-19 by race/ethnicity and income. Am J Prev Med. 2020;59:137-9. https://doi.org/ 10.1016/j.amepre.2020.04.003

3. Bui DP, McCaffrey K, Friedrichs M, LaCross N, Lewis NM, Sage K, et al. Racial and ethnic disparities among COVID-19 cases in workplace outbreaks by industry sector - Utah, March 6-June 5, 2020. MMWR Morb Mortal Wkly Rep. 2020;69:1133-8. https:/ / doi.org/10.15585/mmwr.mm6933e3

4. Hawkins D. Differential occupational risk for COVID-19 and other infection exposure according to race and ethnicity. A J Ind Med. 2020;15:15. PubMed https:/ / doi.org/10.1002/ ajim. 23145

5. Cordes J, Castro MC. Spatial analysis of COVID-19 clusters and contextual factors in New York City [Erratum in: Spat Spatio-Temporal Epidemiol. 2020;36:100399]. Spat Spatio-Temporal Epidemiol. 2020;34:100355. https://doi.org/10.1016/j.sste.2020.100355

6. Rodriguez-Diaz CE, Guilamo-Ramos V, Mena L, Hall E, Honermann B, Crowley JS, et al. Risk for COVID-19 infection and death among Latinos in the United States: examining heterogeneity in transmission dynamics. Ann Epidemiol. 2020;52:46-53.e2. https://doi.org/10.1016/j.annepidem. 2020.07.007

7. Rodriguez-Lonebear D, Barceló NE, Akee R, Carroll SR. American Indian reservations and COVID-19: correlates 
of early infection rates in the pandemic. J Public Health Manag Pract. 2020;26:371-7. https://doi.org/10.1097/ PHH.0000000000001206

8. Waltenburg MA, Victoroff T, Rose CE, Butterfield M, Jervis RH, Fedak KM, et al.; COVID-19 Response Team. Update: COVID-19 among workers in meat and poultry processing facilities - United States, April-May 2020. MMWR Morb Mortal Wkly Rep. 2020;69:887-92.

https://doi.org/10.15585/mmwr.mm6927e2

9. R Core Team. R: a language and environment for statistical computing. Vienna (Austria): R Foundation for Statistical Computing; 2020.

10. Martinez DA, Hinson JS, Klein EY, Irvin NA, Saheed M, Page KR, et al. SARS-CoV-2 positivity rate for Latinos in the Baltimore-Washington, DC region. JAMA. 2020;324:392-5. https://doi.org/10.1001/jama.2020.11374

11. Millett GA, Jones AT, Benkeser D, Baral S, Mercer L, Beyrer C, et al. Assessing differential impacts of COVID-19 on black communities. Ann Epidemiol. 2020;47:37-44. https://doi.org/10.1016/j.annepidem.2020.05.003

12. Moore JT, Ricaldi JN, Rose CE, Fuld J, Parise M, Kang GJ, et al.; COVID-19 State, Tribal, Local, and Territorial Response Team. Disparities in incidence of COVID-19 among underrepresented racial/ethnic groups in counties identified as hotspots during June 5-18, 2020 - 22 states, February-June 2020. MMWR Morb Mortal Wkly Rep. 2020;69:1122-6. https://doi.org/10.15585/mmwr.mm6933e1

13. Hsu HE, Ashe EM, Silverstein M, Hofman M, Lange SJ Razzaghi H, et al. Race/ethnicity, underlying medical conditions, homelessness, and hospitalization status of adult patients with COVID-19 at an urban safety-net medical center - Boston, Massachusetts, 2020. MMWR Morb Mortal Wkly Rep. 2020;69:864-9. https://doi.org/10.15585/ mmwr.mm6927a3

14. Centers for Disease Control and Prevention. Coronavirus disease 2019 (COVID-19): what we can do. 2020 [cited 2020 Sep 15]. https:/ / www.cdc.gov/coronavirus/2019-ncov/ community/health-equity/what-we-can-do.html

15. Rader B, Astley CM, Sy KTL, Sewalk K, Hswen Y, Brownstein JS, et al. Geographic access to United States SARS-CoV-2 testing sites highlights healthcare disparities and may bias transmission estimates. J Travel Med.

2020;27:taaa076. https://doi.org/10.1093/jtm/taaa076

Address for correspondence: NaTasha Hollis, Centers for Disease Control and Prevention, 4470 Buford Highway NE, Mailstop S1064, Atlanta, GA 30341, USA; email: iym7@cdc.gov

\section{EID Podcast: \\ Two Ways of Tracking C. difficile in Switzerland}

Science wields many different tools in the pursuit of public health. These tools can work together to capture a detailed picture of disease. However, many tools accomplish similar tasks, often leaving policymakers wondering, when it comes to disease surveillance, what is the best tool for the job?

Different tests are currently used to diagnose Clostridioides difficile, a dangerous bacterium found in hospitals around the world. As rates of this infection surge globally, researchers need to be able to compare statistics from different hospitals, regions, and countries.

In this EID podcast, Sarah Tschudin-Sutter, a professor/of infectious disease epidemiology at the University Hospital - Basel in Switzerland, discusses using 2 tests for $C$. difficile infection in Europe.

\section{Visit our website to listen: EMERCING https://go.usa.gov/xGEuz INFECIIOUS DISEASES}

